\title{
CONGENITAL MITRAL STENOSIS
}

\author{
BY
}

\author{
J. L. EMERY and R. S. ILLINGWORTH \\ From the Children's Hospital, Sheffield
}

(Received for Publication November 20, 1950)

Two cases of isolated congenital mitral stenosis are presented, because of the great rarity of the condition when properly authenticated by postmortem examination, the doubts about its aetiology, and the difficulty of making a clinical diagnosis.

\section{Case Reports}

Case 1. The patient, a girl and an only child, was admitted at the age of 2 years 6 months with a history of cough, wheezing, and dyspnoea for six months. Previously she had been perfectly well with no history of cyanosis. She was found to have signs of a right basal pleural effusion. There was no cyanosis and no clubbing of the fingers, and no other abnormal physical signs were found. A chest radiograph showed an effusion, collapse of the right middle lobe, and a general non-specific increase of lung markings. The intradermal tuberculin test to a strength of $1 \mathrm{mg}$. was negative, and the diagnosis made was simple pleural effusion of unknown origin. The effusion persisted, but she remained fairly well for the next four months. She then developed severe dyspnoea, pitting oedema over the sacrum, distension of the neck veins, and enlargement of the liver to the umbilicus. The clinical diagnosis was changed to that of congestive heart failure of unknown aetiology. At no time were any abnormal physical signs found in the heart. No murmurs were heard. The blood pressure was $125 / 90$. She was given digitalis and a low sodium diet, but failed to respond to treatment and died six months after admission, at the age of 3 years.

The pleural effusion was aspirated on three occasions, $200 \mathrm{ml}$. straw-coloured fluid being withdrawn on the first occasion, $580 \mathrm{ml}$. on the second, and $130 \mathrm{ml}$. on the last.

SPeCial Investigations. There was no apparent cardiac enlargement on radiography.

The pleural fluid contained an equal mixture of mononuclear and polymorphonuclear leucocytes, and was sterile on culture. There were elastic fibres and bacilli, mostly Gram-negative, in the sputum.

The urine had a trace of albumin, and a few red cells in a centrifuged deposit.

The Wassermann reaction was negative.

A blood count gave Hb. 10 g. \%, and R.B.C.s $4 \cdot 3 \mathrm{~m}$. per c.mm.

There was nothing of note in the pregnancy history.

NECROPSY. The gross naked eye appearance of the body cavities and organs was of chronic venous congestion. There was a bilateral pleural effusion with adhesions on the right side.

The heart (Fig. 1) weighed $90 \mathrm{~g}$. (normal for age of child 57 g., Coppoletta and Wolbach, 1933). The right auricle appeared normal and was $1-1.5 \mathrm{~mm}$. thick. The tricuspid valve had a margin of $62 \mathrm{~mm}$. and showed no thickening. The right ventricle was $3 \mathrm{~mm}$. thick and the pulmonary valve (margin $30 \mathrm{~mm}$. in circumference) also appeared normal. The left auricle was enlarged, the endocardium pale, the muscle $3 \mathrm{~mm}$. thick. The mitral valve was thick and rigid, the margin being $30 \mathrm{~mm}$. The left ventricle did not appear enlarged; the muscle was $5-7.5 \mathrm{~mm}$. thick. The aortic valve appeared normal, with a margin of $31 \mathrm{~mm}$. The foramen ovale and ductus arteriosus were completely obliterated. The aorta and great vessels appeared normal.

On microscopy, the thickened endocardium, the mitral valve and the bands of the tissue extending into the heart muscle were seen to consist of collagenous tissue varying from loose fibrillary to a dense, almost cartilaginous structure. No foci of cellular infiltration or Aschoff nodes could be found either amongst the fibrous tissue or in any sections of the heart muscle, including the interventricular septum. The coronary vessels were normal and there were few vessels in the connective tissue of the stenosed valve and auricular endocardium. The diaphragm and pericardium showed an increase in collagenous tissue but no evidence of inflammatory change. In the lung almost all the alveoli had large numbers of haemosiderin-containing phagocytes. Small areas of bronchopneumonia were present. Other organs showed no lesions other than venous congestion.

Case 2. The patient, a girl, was admitted at the age of 17 months with a history that until two weeks previously she had been perfectly well. She then developed a cough and fever, her respirations became rapid, her alae nasi were working, and she was generally poorly. She vomited two days before admission.

On admission she was acutely ill, with dyspnoea, cyanosis, and signs of extensive bronchopneumonia (pulse 160 , temperature $102^{\circ}$, and respirations about 60 per minute). There was a triple rhythm at the cardiac apex, but at that time, probably owing to the high respiration rate and gross signs in the chest, no murmur was heard. The tip of the spleen was felt. There was no clubbing of the fingers. A diagnosis of bronchopneumonia was made and confirmed radiologically. 

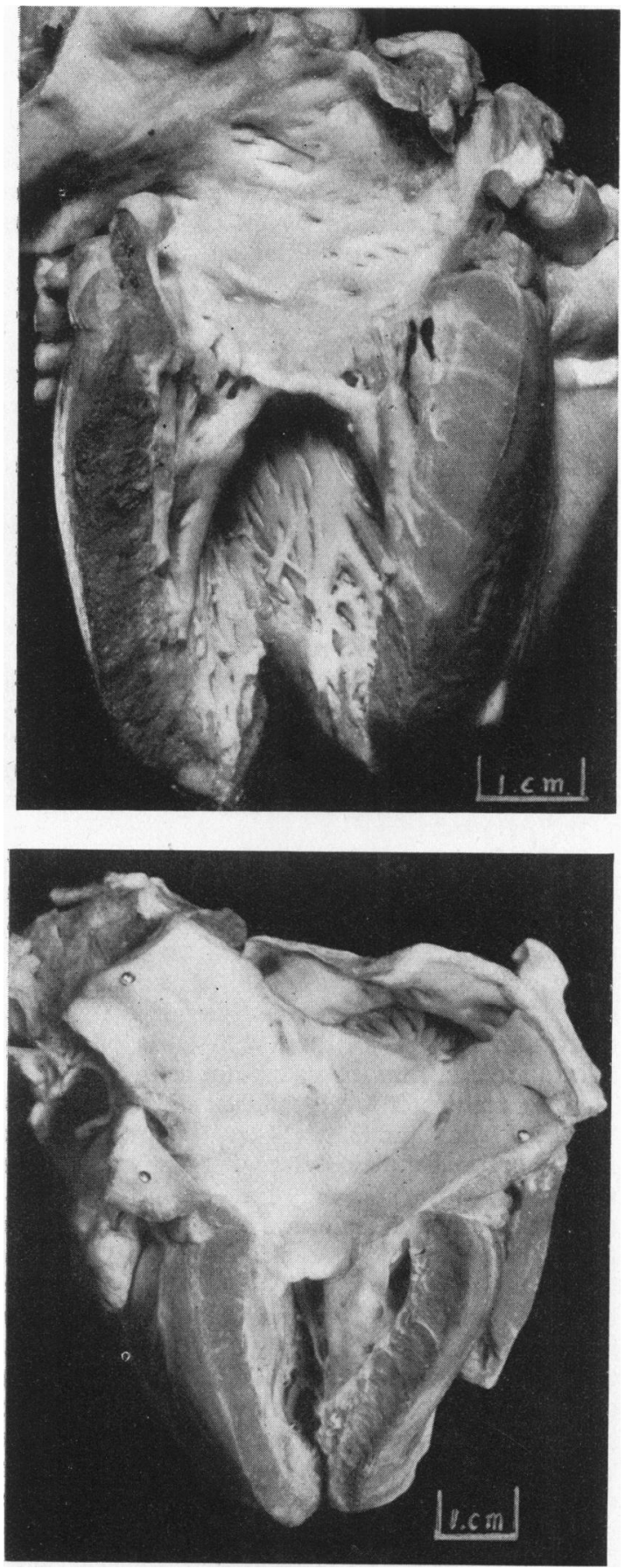

FIGS. 1 and 2.-Photographs of the left side of the heart showing pale thickened endocardium in a dilated auricle, thickening of the mitral valve and short thick chordae tendineae. Pale strands of fibrous tissue may also be seen penetrating the ventricular muscle.
She was treated with sulphamezathine and aluminium procaine penicillin and in four days was greatly improved and the cyanosis had disappeared. Seven days later she had a relapse, and the findings were similar to those in the first attack. This time two murmurs were heard at the apex, and there was some disagreement as to which of the two, systolic or diastolic, was the louder. The phonocardiogram showed that the diastolic murmur was louder than the systolic. The liver was enlarged, reaching to the umbilicus, and the veins of the neck were engorged. Congestive heart failure with superimposed bronchopneumonia was diagnosed, and it was thought that the probable cause was congenital mitral stenosis. The question of superimposed subacute bacterial endocarditis was considered, and penicillin was given, but the blood culture was negative. She was given digitalis, and made considerable improvement in four or five days, the temperature again subsiding to normal. She relapsed a month after admission and died.

Special Investigations. An intradermal Mantoux test (0.1 mg.) was negative.

A radiograph of the chest showed signs which, it was thought, were due partly to pulmonary congestion and partly to superimposed bronchopneumonia. There was no apparent cardiac enlargement until a few days before death.

The urine was normal.

An E.C.G. showed a moderate right axis deviation.

A blood count gave Hb. $9 \cdot 6$ g. \%, R.B.C.s $3 \cdot 8$ m. per c.mm.

A postnasal swab gave a coagulase positive culture of Staph. aureus.

Pregnancy had been uneventful. There was no evidence of any infection.

NECROPSY. The body was that of a well nourished female child. There was no generalized oedema. Both pleural cavities contained small amounts of strawcoloured fluid. The lungs were heavy and deep red, the right lower lobe having an area of fibrinous pleurisy.

The heart (82 g., normal for age 45 g.) had a small, pale area of fibrous tissue over the anterior aspect of the apex of the right ventricle (Fig. 2). The right auricle was normal, the tricuspid valve, with a margin of $57 \mathrm{~mm}$., appeared normal. The right ventricle was $4 \mathrm{~mm}$. thick and its cavity was normal. The pulmonary valve was normal (margin $35 \mathrm{~mm}$.). The left auricle was increased in size, the wall measuring $2-4 \mathrm{~mm}$. in thickness, lined by a pale fibrous layer 0.5-1 mm. thick. The mitral valve cusps were pale, thickened and rigid, the circumference of aperture being $25 \mathrm{~mm}$. The left ventricle appeared of normal size, 7-8 mm. thick. There were pale areas in the muscle, particularly in the papillae leading to the mitral valve. The aortic valve had a thickened edge, maximal at the mid-portion of each cusp, the bases being relatively normal. The internal circumference was $28 \mathrm{~mm}$. The coronary arteries were normal. The foramen ovale was completely obliterated. The ductus was just patent, with a circumference of about $2 \mathrm{~mm}$. The great vessels appeared normal. Histologically the heart showed lesions very similar to those in case 1 , the only difference being that the areas of fibrosis corresponding to the pale areas seen by the 
naked eye were smaller but more widely scattered. No vascular or inflammatory lesions could be found. The lungs did not show pneumonia, but the alveoli contained large numbers of haemosiderin-laden macrophages. The diaphragm and pericardium showed a general increase in connective tissue, but no inflammatory changes. Other organs showed no lesions other than venous congestion.

Summary of Cases. Both of these children died with venous congestion as the major presenting feature.

The gross anatomical lesion in the heart consisted of mitral stenosis with fixation of the valves, an increase in fibrous tissue throughout the left auricle, and areas of fibrosis in the left ventricle. In one case there was a slight increase in the connective tissue of the aortic valve. The foramen ovale in both instances was completely obliterated and there was no defect in the inter-auricular or ventricular septa.

Histologically the fibrous tissue was avascular. There was no associated inflammatory reaction and no Aschoff tissue could be found.

\section{Discussion}

Taussig (1947) aptly summarizes the present state of our knowledge of such cases:

\begin{abstract}
' Not uncommonly autopsy reveals a condition in which it is wellnigh impossible to determine whether the abnormality in the mitral valve was due to a congenital malformation or to an acquired rheumatic infection.'
\end{abstract}

There are three well accepted causes of cardiac lesions in very young children: (1) congenital deformity; (2) foetal endocarditis; (3) infantile rheumatic heart disease.

The nature of a congenital deformity of the heart depends largely upon the stage in development at which the abnormality begins. In the case of mitral atresia with septal defect the abnormal growth must begin before the complete formation of the septum. If, however, the abnormal growth begins after the fourth month the septa would be intact and mitral stenosis anatomically similar to the adult disease could occur. The complete closure of the foramen ovale in these cases at first sight appears to be the shutting of a convenient shunt, but the foramen acts as a valve facilitating blood flow from right to left and only if the obliterating fold is incomplete does it enable blood to flow from left to right. An increased pressure in the left auricle is likely to keep the foramen permanently closed.

Valvular lesions in neonatal hearts are mostly ascribed to foetal endocarditis. Farber and Hubbard (1933) found ten such cases in the literature and added four of their own. They appear to consider the presence of fibrosis and calcification as sufficient evidence for their inflammatory origin, though two of their own cases showed other signs of inflammation. Gross (1941), in a critical discussion and review of so-called foetal endocarditis, regards the concept as untenable. He draws attention to the absence of inflammatory change in reports of these cases, and to the similarity of the myocardial lesions to healed bland infarcts due to vascular occlusion. A large number of foetal deaths are associated with cardiac abnormalities, and it seems surprising, if foetal endocarditis does occur apart from congenital syphilis, that there is such an extreme dearth of reports of active endocarditis in foetal hearts. We, in fact, are not acquainted with any such report. The increased connective tissue in these abnormal hearts appears to be normal tissue but in abnormal amounts, and it gives little support to the theory of foetal endocarditis. The evidence is completely circumstantial and negative, and one can hardly help but conclude that the lesions are congenital in origin, and analogous to other congenital deformities of the heart, in which abnormal growth begins relatively late in the heart's development.

There have been several reports of rheumatic carditis in infants (Kissane and Koons, 1933; Ferguson, 1893; McIntosh and Wood, 1935; Eigen, 1938). McIntosh and Wood showed, from a combination of figures from various workers, that $1 \cdot 3 \%$ of 2,884 cases of rheumatic fever occurred in the first three years of life. They described 24 cases of their own in which the disease occurred in the first two years with necropsy findings in six, in all of which hyaline degeneration and Aschoff tissue was found. Eigen's case, an infant 2 years old, showed the characteristic histological features of rheumatic heart disease, with areas of cellular infiltration and necrosis with giant cells.

In an analysis of 1,700 children with rheumatism Walsh, Bland, and Jones (1940) found that the minimum time for the development of mitral stenosis was three years and in only five of their 48 cases of mitral stenosis did the lesion develop in five years from the onset of recognizable disease. If the infants under the age of 2 dying with mitral stenosis had had rheumatic disease of the heart, the process must have been uncommonly rapid and complete to have produced the lesion and for it to have become completely scarred and inactive. The children who have died with known rheumatic heart disease in this age period have shown histological evidence of rheumatism. The valvular and endocardial lesions in rheumatic heart disease characteristically show a permanent increased vascularity (Koletsky, 1946), whereas the valvular and endocardial lesion in the two cases of mitral stenosis that we have examined do not show such change.

It is felt, that whilst acute rheumatism does occur 
in children under the age of 3 , the presence of fibrosis in the heart in areas frequently affected by rheumatic scarring later in life does not constitute a proof of the rheumatic aetiology of the infantile lesions.

Mitral stenosis is much less common in infantile deformities of the heart than in mitral atresia, Manhoff and Howe listing 28 cases of atresia in 1945. Mitral atresia is usually associated with gross deformity of the heart and with auricular septal defect, but cases of mitral stenosis, such as the two cases here described, form a small group of heart deformities in which the mitral valve is affected alone, or with deformity of the aortic valve, and without any defect in the auricular or ventricular septa. Such cases of mitral stenosis without septal defects, and confirmed by necropsy, have been described by Day (1932), Johnson and Lewes (1945), McConnell (1950), Eigen (1938), and Newns (1938). The cases described by the first three authors showed a histological picture similar to our cases -an increase of connective tissue without inflammatory change-and our argument, suggesting a developmental abnormality, applies in their cases as in our two cases. Eigen's case has already been mentioned. There is no mention of the histology in Newns' case.

The clinical picture in case 1 was particularly confusing owing to the absence of cardiac murmurs. It is known that such a difficulty may arise in mitral stenosis.

\section{Summary.}

Two cases of congenital mitral stenosis are described.
One presented for four months as a right basal pleural effusion, and had no cardiac murmurs at any stage. The clinical diagnosis was then changed to one of congestive heart failure of unknown aetiology. The second presented as bronchopneumonia superimposed on congestive heart failure, and the characteristic murmur was found. Death in each case was due to congestive heart failure.

The lesions in the heart appeared to be congenital in origin and due to abnormal development after the cavities of the heart had been fully formed. No evidence of foetal endocarditis or of a rheumatic process could be found.

\section{REFERENCES}

Coppoletta, J. M., and Wolbach, S. B. (1933). Amer. J. Path., 9, 55.

Day, H. B. (1932). Lancet, 1, 1144.

Eigen, L. A. (1938). Amer. Heart. J., 16, 363.

Farber, S., and Hubbard, J. (1933). Amer. J. med. Sci., 186, 705.

Ferguson, J. H. (1893). Edinb. Hosp. Rep., 1, 608.

Gross, P. (1941). Arch. Path., Chicago, 31, 163.

Johnson, R. S., and Lewes, D. (1945). Brit. Heart J., $7,52$.

Kissane, R. W., and Koons, R. A. (1933). Arch. intern. Med., 52, 905.

Koletsky, S. (1946). Amer. J. Path., 22, 351.

McConnell, B. E. (1950). Archives of Disease in Childhood, 25, 186.

McIntosh, R., and Wood, C. L. (1935). Amer. J. Dis. Child., 49, 835.

Manhoff, L. J., and Howe, J. S. (1945). Amer. Heart J., $29,90$.

Newns, G. H. (1938). Proc. roy. Soc. Med., 31, 1129.

Taussig, H. B. (1947). 'Congenital Malformations of the Heart,' p. 358. New York.

Walsh, B. J., Bland, E. F., and Jones, T. D. (1940). Arch. intern. Med., 65, 321. 